\title{
Assembly of HCV E1 and E2 glycoproteins into coronavirus VLPs
}

\author{
Brief Report \\ N. Jourdan ${ }^{1,2}$, G.-J. Godeke ${ }^{3}$, M. Penaud ${ }^{2}$, G. Mottola ${ }^{1}$, A. Sorrentino ${ }^{1}$, \\ P. J. M. Rottier ${ }^{3}$, and S. Bonatti ${ }^{1}$ \\ ${ }^{1}$ Dipartimento di Biochimica e Biotecnologie Mediche, \\ Università di Napoli "Federico II", Napoli, Italy \\ ${ }^{2}$ Laboratoire de Thérapie Génique, INSERM UMR U649, \\ CHU Hôtel Dieu, Nantes, France \\ ${ }^{3}$ Virology Division, Department of Infectious Diseases and Immunology, \\ Veterinary Faculty, Utrecht, The Netherlands
}

Received January 3, 2006; accepted March 9, 2006

Published online May 3, 2006 (C) Springer-Verlag 2006

Summary. Hepatitis C virus (HCV) is believed to assemble by budding into membranes of the early secretory pathway, consistent with the membrane location where the viral envelope glycoproteins E1 and E2 accumulate when expressed. Coronavirus assembly also takes place at pre-Golgi membranes. Here, we generated coronavirus-like particles carrying in their envelope chimeric HCV glycoproteins composed of the ectodomains of E1 and E2, each fused to the transmembrane plus endodomain of the mouse hepatitis coronavirus spike glycoprotein. The chimeric particle system will enable structural and functional studies of the HCV glycoproteins.

\section{$*$}

Hepatitis $\mathrm{C}$ virus (HCV) is the major etiological agent of human non-A, non-B hepatitis [4, 17] and has infected millions of people worldwide [20]. This flavivirus causes chronic liver disease for which treatment options are limited and no vaccine is yet available. The study of its biology has been severely hampered by the lack of viral culture systems, a situation that has recently changed by the generation of infectious HCV genomes that replicate efficiently in cell culture [21, 37, 38].

Little is still known about the biogenesis and structure of HCV particles. The virus is composed of a core (C) protein - that packages the positive-stranded RNA genome - and envelope proteins, E1 and E2, which are generated by cleavage 
from the single precursor polyprotein, translated from the genomic RNA. E1 and particularly E2 are heavily $\mathrm{N}$-glycosylated proteins anchored in membranes by their C-terminal hydrophobic domain. Expression studies have shown the glycoproteins to be retained in early compartments of the secretory pathway, consistent with the supposed localization of HCV assembly in the endoplasmic reticulum (ER) [7, 23, 26, 27].

Several workers have resorted to surrogate models to enable the analysis of interactions of E1 and E2 in particle assembly and their role in the initiation of viral infection. VSV pseudotype viruses were generated carrying HCV glycoprotein ectodomains joined to the VSV G protein's transmembrane and cytoplasmic domain [3, 19, 24, 25]. Unmodified HCV glycoproteins were assembled into retroviral and lentiviral particles $[1,6,9,14,22,36]$. These pseudotype systems have one drawback in that particles are assembled at the plasma membrane rather than at the intracellular membranes or, as recently demonstrated, into multivesicular bodies [29], a late endosomal compartment that can fuse with the cell surface [12], whilst HCV assembly and budding most probably occur at the membrane of secretory pathway organelles. Under these different conditions, the glycosylation state of the assembling glycoproteins and the lipid composition of the resulting particles are clearly different, and the biological consequences of these differences are unknown. For this reason, the present study aimed at developing a coronavirus-based pseudotype system.

Coronaviruses are enveloped, plus-sense RNA viruses formed by budding into membranes of the intermediate compartment (IC) and ER [15, 16, 32]. They consist of a capsid, formed by the nucleocapsid $(\mathrm{N})$ protein-packaged genomic RNA, surrounded by an envelope containing three proteins: $\mathrm{M}, \mathrm{E}$ and $\mathrm{S}$. The $\mathrm{M}$ and $\mathrm{E}$ protein, the major and minor membrane constituent, respectively, are able to

Fig. 1. Construction and expression of chimeric E1-S and E2-S genes. A E1-S and E2-S proteins are composed of the signal sequence and ectodomain (aa 171-346 and 364-700) of the $\mathrm{HCV}$ precursor polypeptide, respectively, fused to the 60-residue transmembrane (TMD) plus endodomain $(E D)$ from the MHV strain A59 S protein. B Cultures of vTF7-3 infected OST-7 cells, transfected or mock-transfected, were pulse labeled with ${ }^{35} \mathrm{~S}$-labeled amino acids from 5 to $8 \mathrm{~h}$ post infection. Cell lysates were prepared and immunoprecipitations carried out with (a) the anti-E2 MAb 185 and (b) the anti-E1 MAb A4. The immunoprecipitates were subjected to SDS-PAGE. Numbers on the left indicate the positions in the same gel of marker proteins. C Similar expressions were performed in Huh-7 cells. At $5 \mathrm{~h}$ post infection the cells were fixed, permeabilized, double-stained by indirect immunofluorescence, and analysed by confocal microscopy. E1-S was immunostained with the anti-E1 MAb A4, E2-S with either the anti-E2 MAb 185 or the R21 polyclonal anti-E2 antibody (panels $\mathbf{a}$ and $\mathbf{h}$, respectively), the ER marker calreticulin with a rabbit anti-calreticulin polyclonal antibodies (StressGen), and the intermediate compartment marker ERGIC-p53 with the MAb G1/93 directed against ERGICp53 [30]. Texas red- and fluorescein-conjugated secondary antibodies were from Jackson Laboratories and Bioatlantic. Fluorescence was observed with a Leica TCS Spectral (SP1) equipped with a DMR inverted microscope and $63 \times$ objective with a numerical aperture of 1.4. For each line the same horizontal focus is shown. Colocalisation of Texas red and fluorescein was analysed in the merge image and quantified by using MetaMorph. Bars, $10 \mu \mathrm{m}$ 
self-assemble into VLPs that are secreted from cells [35]. The spike (S) protein is a type I membrane protein responsible for receptor binding and membrane fusion. It is not essential for particle assembly but is incorporated by interactions of its $\mathrm{C}$-terminal domain with the $\mathrm{M}$ protein. Its ectodomain can be exchanged by that of other coronavirus S proteins or that of the VSV G protein, giving rise to chimeric viruses or VLPs $[2,11,13,18]$. Here, we demonstrate that similar replacements allow the incorporation of the HCV glycoproteins into coronavirus VLPs.

We generated chimeric HCV envelope constructs encoding the ectodomain of E1 or E2 protein fused to the transmembrane and endodomain of the mouse

A

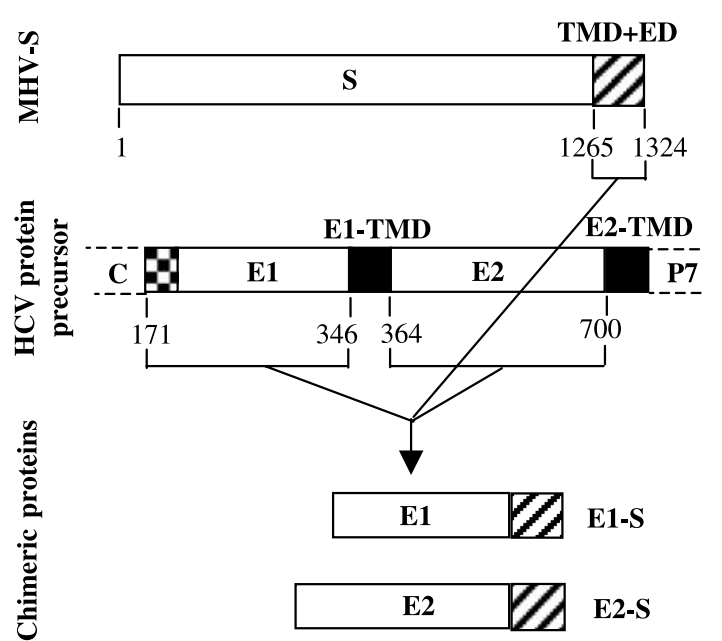

B

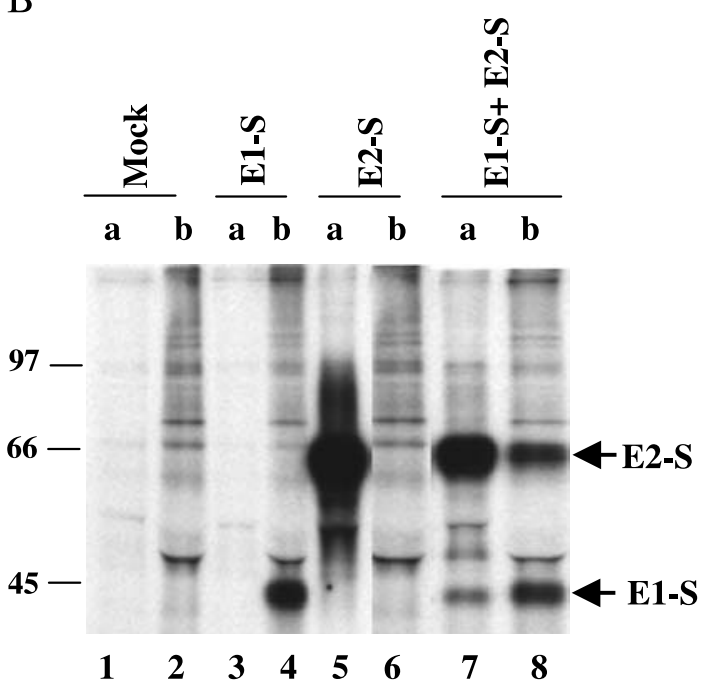

$\mathrm{C}$
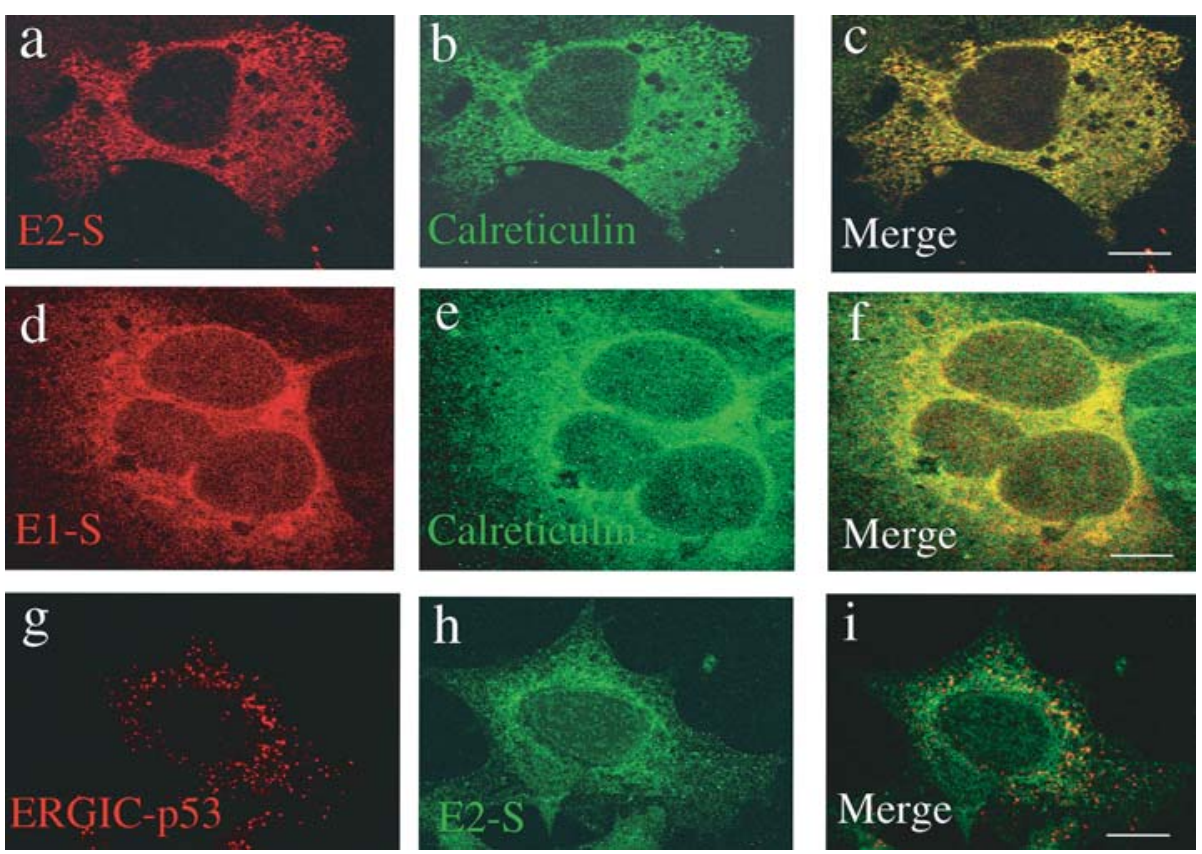
hepatitis virus (MHV) S protein. The E1-S and E2-S chimeric genes were generated by a two-step PCR overlapping procedure using the $\mathrm{S}$ sequences from the plasmid pTUMS [33] and E1 and E2 sequences from the full-size cDNA of HCV strain BK [31]. The PCR products were cloned into pTUG3 [34], behind the bacteriophage $\mathrm{T} 7$ promoter for transcription. The resulting constructs are depicted in Fig. 1A. Expression of the chimeric proteins was studied in murine OST-7 cells [8] by first infecting with a recombinant vaccinia virus expressing the bacteriophage T7 RNA polymerase (v-TF7-3) [10] and subsequently transfecting the cells with the plasmids, separately and together. The cells were labelled with ${ }^{35} \mathrm{~S}$-amino acids from $5-8 \mathrm{~h}$ post-infection (p.i.), cell lysates were prepared, and immunoprecipitations carried out with anti-E1-specific (b) and anti-E2-specific (a) monoclonal antibodies (MAb), after which the resulting proteins were subjected to SDS-PAGE. As shown in Fig. 1B, both chimeric proteins were produced, E1-S and E2-S migrating with apparent molecular masses of approximately 44 and $64 \mathrm{kDa}$, respectively.

The subcellular distribution of E1-S and E2-S was analysed in Huh7 cells. Single- and double-transfected Huh7 cells were stained with specific antibodies and viewed by confocal immunofluorescence microscopy. In single-transfected cells (Fig. 1C) as well as in double-transfected cells (not shown), both E1-S and E2-S appeared in a perinuclear reticular pattern (panels a and d) fully superimposable by the staining pattern of calreticulin, an ER resident protein (panels $c$ and $\mathrm{f}$ ). This pattern was dramatically different from the punctuate profile exhibited by the IC marker ERGIC-p53, as illustrated for E2-S (panels g-i). It is clear that the chimeric proteins are retained in the ER, similarly to the native E1 and E2 glycoproteins.

Next, we studied whether the E1-S and E2-S glycoproteins can be assembled into coronaviral VLPs. Initially, we analyzed whether the co-expression with the MHV strain A59 $\mathrm{M}$ and E proteins would change the E1-S and E2-S staining pattern (incorporation into VLPs should result in accumulation in the Golgi apparatus, where cargo destined for secretion concentrates). The E1-S protein coexpresssed with $\mathrm{M}+\mathrm{E}$ (Fig. 2A, panels a-f) or additionally with E2-S (not shown) was observed to display essentially the same reticular staining profile, overlapping with calreticulin (Fig. 2A, panel a-c), that we observed after single expression of the chimeric protein (Fig. 1C, panels $\mathrm{d}-\mathrm{f}$ ). However, a significant fraction, representing about $20 \%$ of the E1-S staining, as quantified using MetaMorph, was excluded from the ER staining as observed in the merge image. The same proportion of E1-S staining coincided with the coronavirus M protein (Fig. 2A, panels $\mathrm{d}-\mathrm{f}$ ), which is known to accumulate in the IC and Golgi complex [15, 16]. This shift in staining was even more significant when co-expressing the E2-S protein with $\mathrm{M}$ and $\mathrm{E}$, both in the absence (Fig. 2A, g-1) and in the presence of E1-S (not shown). Now, about $60 \%$ of the E2-S staining signal colocalized with ERGIC-p53 and co-accumulated with the coronavirus M protein. Under the same experimental conditions, a dual labelling of both calreticulin and ERGICp53 (Fig. 2B) did not reveal any overlap of staining signal, indicating that the morphology and integrity of the organelles is well maintained. The appearance of E1-S and, particularly, E2-S in the IC and Golgi complex when co-expressed with 

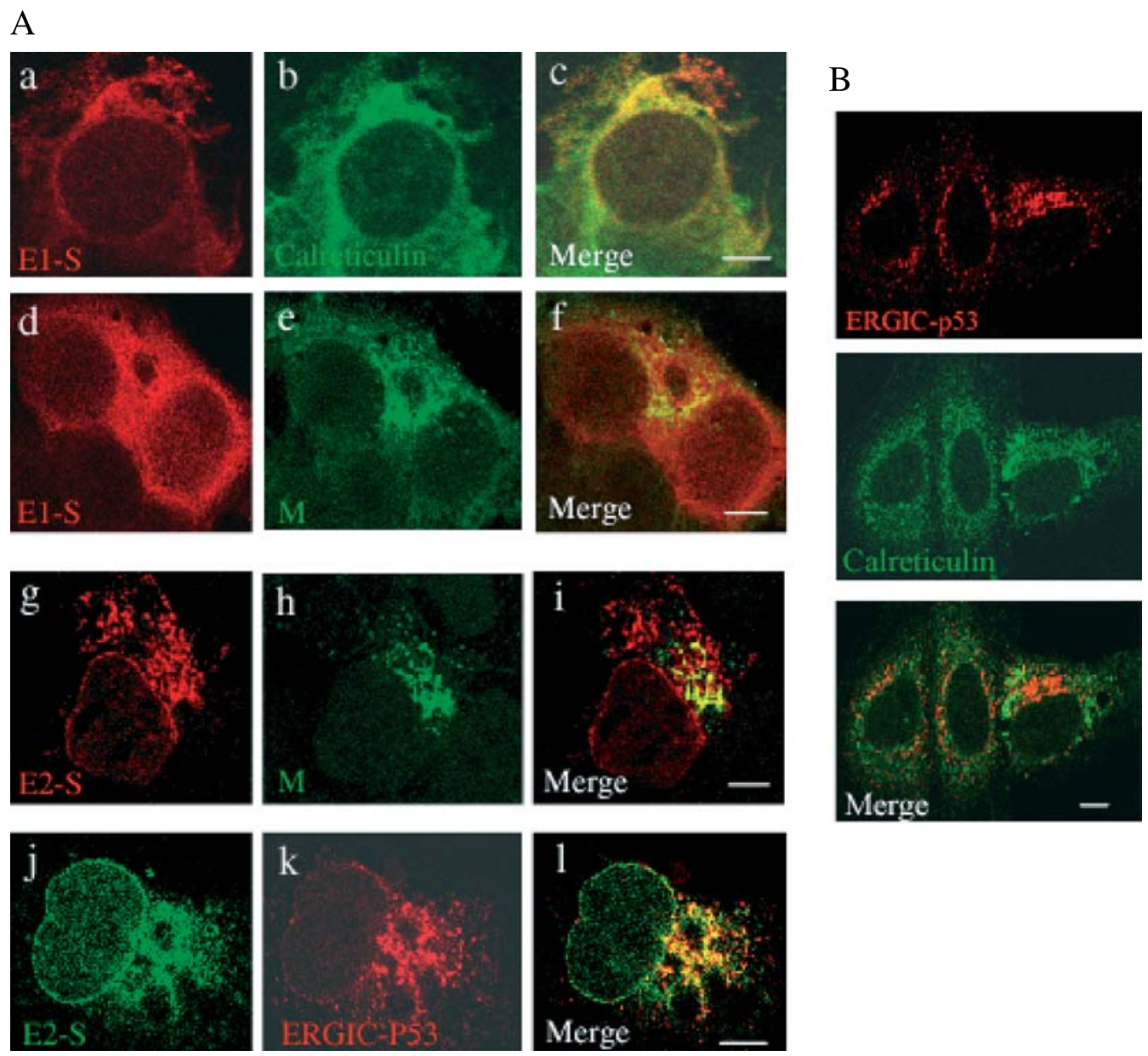

Fig. 2. Effect of co-expression of MHV M and E proteins on the subcellular localisation of E1-S and E2-S. Expressions were carried out in Huh-7 cells by vTF7-3 infection and transfections with plasmids encoding for M, E, E1-S, and E2-S proteins. At $5 \mathrm{~h}$ post infection, the cells were analysed by double-staining indirect immunofluorescence confocal microscopy. E1-S was immunostained with the anti-E1 MAb A4 and Texas Red ${ }^{\circledR}$ dye-conjugated goat antimouse IgG. The ER marker calreticulin was stained with rabbit anti-calreticulin polyclonal antibodies and fluorescein-conjugated sheep anti-rabbit $\mathrm{IgG}$. The coronavirus $\mathrm{M}$ protein was stained with the rabbit polyclonal anti-MHV antibody k134 [28] and fluorescein-conjugated anti-rabbit IgG. E2-S was immunostained with either the anti-E2 MAb 185 (A, panel g) and Texas Red ${ }^{\circledR}$ dye-conjugated goat anti-mouse IgG or the R21 polyclonal anti-E2 antibody (A, panel j) and fluorescein-conjugated sheep anti-rabbit IgG. The intermediate compartment marker ERGIC-p53 was stained with the MAb G1/93 and Texas Red ${ }^{\circledR}$ dye-conjugated goat anti-mouse $\mathrm{IgG}$. For each line, the same horizontal focus is shown and colocalisation of Texas red and fluorescein was analysed in the merge image and quantified by using MetaMorph.

Bars, $10 \mu \mathrm{m}$

the $\mathrm{M}$ and E proteins, suggests that the proteins are indeed incorporated into VLPs, thereby enabling them to leave the ER and funnel into the post-ER compartments for secretion out of the cell. 
Finally, incorporation of the chimeric E1-S and E2-S proteins into coronavirus VLPs was investigated by biochemical analysis as described before [11]. OST-7 cells were infected with vTF7-3 and transfected with combinations of plasmids
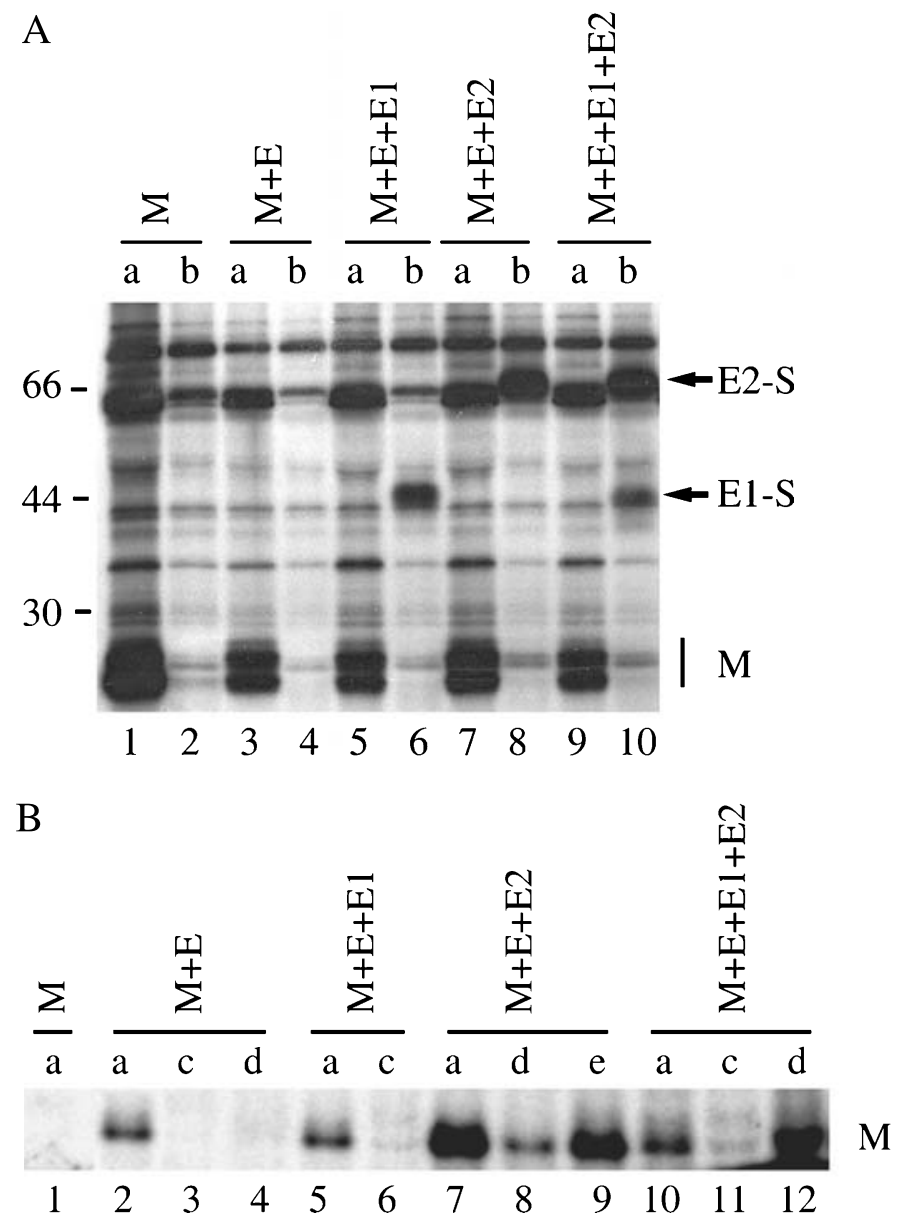

Fig. 3. Incorporation of chimeric E1-S and E2-S proteins into coronavirus VLPs. OST-7 cells were infected with vTF7-3 and transfected with different combinations of plasmids coding for the MHV M and E proteins and the chimeric E1-S and E2-S proteins. Cells were labeled with ${ }^{35} \mathrm{~S}$-labeled amino acids from 5 to $8 \mathrm{~h}$ post infection, after which the cells and culture media were harvested separately. A Cells were lysed with detergent lysis buffer (10 mM Tris-HCl, (pH 7.4), $150 \mathrm{mM} \mathrm{NaCl}, 1 \mathrm{mM}$ EDTA, $1 \%$ Triton X100, $20 \mathrm{mM}$ N-ethylmaleimide, and 1 tablet of Protease Inhibitor Mixture (Roche) per $40 \mathrm{ml}$ ) and then processed for immunoprecipitation with the polyclonal anti-MHV rabbit serum k134 (lanes a) and with the peptide antibody W699 directed against the carboxy-terminal tail of the S protein (lanes $b$ ), and processed for SDS-PAGE. Molecular masses of marker proteins are indicated at the left, the positions in the gel of the chimeric proteins and of the $\mathrm{M}$ protein forms are indicated at the right. B VLPs isolated from the culture media were affinity purified with the polyclonal anti-MHV rabbit serum k134 (lanes $a$ ), the anti-E1 MAb A4 (lanes $c$ ), the conformation-independent anti-E2 MAb 185 (lanes $d$ ), or the conformation-dependent anti-E2 MAb 166 (lane $e$ ), and analysed by SDS-PAGE 
encoding the coronaviral and chimeric proteins. They were labelled with ${ }^{35} \mathrm{~S}$ amino acids for $3 \mathrm{~h}$ starting at $5 \mathrm{~h}$ p.i., after which (i) the cells were analysed to check the expression of the proteins, and (ii) the culture media were processed to study the presence and composition of VLPs. For the analysis of the expressed proteins, detergent lysates of the cells were prepared and subjected to immunoprecipitations. As shown in Fig. 3A, the synthesis of the M protein was obvious from the appearance of the characteristic bands representing different O-glycosylation forms, which were precipitated using a polyclonal anti-MHV serum (lanes a). The synthesis of the E1-S and E2-S proteins was analyzed using a peptide antiserum directed against the MHV S protein carboxy-terminal tail, which should be able to immunoprecipitate both chimeric proteins. The appropriate bands clearly appeared when the proteins were co-expressed with $\mathrm{M}$ and $\mathrm{E}$ either alone or together (lanes 6, 8 and 10) and were absent when E1-S and E2-S had not been expressed (lanes 2 and 4 ).

The VLPs released into the culture media were first purified by flotation through discontinuous sucrose density gradients as described earlier [11]. In this procedure, membranous particles and their associated proteins float to the top of the gradient during centrifugation, whereas proteins not associated with lipids remain in the more dense parts of the gradient. The presence, at the top of the appropriate gradients, of the typical spherical particles seen earlier for coronaviral VLPs [11] was confirmed by electron microscopy (data not shown). In order to establish whether the chimeric E1-S and/or E2-S proteins had been incorporated into these particles, we performed immunoprecipitations on samples of the top fraction of each gradient using antibodies directed against the E1 or E2 proteins, followed by PAGE. These analyses did not allow the direct demonstration of the chimeric proteins in any of the relevant samples, due probably to a too-low efficiency of incorporation. We therefore made use of an indirect assay used earlier for the sensitive detection of glycoproteins incorporated into coronaviral VLPs $[2,5,11]$. This assay involves the affinity-purification of intact VLPs using antibodies against the E1 or E2 protein and the subsequent analysis of the sample by PAGE, using the presence or absence of the M protein as the read-out parameter for VLP capture and, hence, for the presence or absence, respectively, of the chimeric protein in the particles. As a control to verify VLP release, a similar affinitypurification is done using the polyclonal anti-MHV serum, which recognizes epitopes in the M protein's ectodomain. The results of such analyses are shown in Fig. 3B, which first of all reveals that the negative control, single expression of the $\mathrm{M}$ protein, was indeed not productive (lane 1). The positive control, co-expression of $\mathrm{M}$ and E proteins, yielded VLPs that could be isolated with the MHV antiserum (lane 2), but these particles were not recognized by MAb directed against E1 or E2 (lanes 3 and 4, respectively). In cells co-expressing M and E together with E1-S or E2-S or both, VLPs had been produced, as revealed by the anti-MHV serum (lanes 5, 7 and 10). These VLPs had incorporated E1-S and E2-S chimeric proteins, since they could be isolated by both anti-E1 (lanes 6 and 11) and anti-E2 MAb (lanes 8,9 and 12). Though clearly positive as compared to the negative control (lane 3), the M protein band obtained after immuno-isolation with the anti-E1 
MAb was always much weaker than with the antibodies directed against E2. This difference may relate to the different expression levels of the two proteins (see also Fig. 3A) or to the different qualities (affinities) of the antibodies, or it may indicate that E1-S is incorporated less efficiently than E2-S. The latter interpretation is consistent with the results of the immunofluorescence studies of Fig. 2, which showed that in the presence of the $M$ and E proteins, a larger fraction of E2-S than of E1-S escapes from the ER.

In conclusion, the results obtained consistently indicate that E1-S and E2-S can be incorporated into coronavirus VLPs and subsequently secreted with these particles. This incorporation occurred in early membranes of the secretory pathway, as the chimeric proteins were able to move out from the ER only when co-expressed with the coronavirus envelope proteins that assemble at ER and IC membranes. Because these HCV chimeric particles have the lipid composition of early, i.e. pre-Golgi membranes, and because the E1 and E2 glycoproteins in these particles are processed and become mature in much the same way as during normal infection, they presumably mimic the native HCV particle very closely. They should therefore be suitable for studying early infection steps of HCV that require specific interactions with proteins and lipids of the target cell and might be tested for their vaccine potential. Finally it seems feasible now to integrate the chimeric E1-S and E2-S genes into the background of an attenuated MHV genome, replacing the $\mathrm{S}$ gene and generating chimeric viruses that allow safe studies of the early steps in the HCV life cycle.

\section{Acknowledgments}

We thank G. Migliaccio for the Huh7 cells and the anti-E2 antibodies 185 and R21; A. Nicosia for the anti-E2 antibody 166; H. Greenberg and J. Dubuisson for the anti-E1 antibody A4; H. P. Haury for the ERGIC-p53 MAb; P. Masters for the W699 antibody; C. Colombeix for help with MetaMorph, and C. Sapin, K. Murray and V. Marechal for critical reading of the manuscript.

\section{References}

1. Bartosch B, Dubuisson J, Cosset FL (2003) Infectious hepatitis C virus pseudo-particles containing functional E1-E2 envelope protein complexes. J Exp Med 197: 633-642

2. Bosch BJ, de Haan CA, Smits SL, Rottier PJ (2005) Spike protein assembly into the coronavirion: exploring the limits of its sequence requirements. Virology 334: 306-318

3. Buonocore L, Blight KJ, Rice CM, Rose JK (2002) Characterization of vesicular stomatitis virus recombinants that express and incorporate high levels of hepatitis $\mathrm{C}$ virus glycoproteins. J Virol 76: 6865-6872

4. Choo QL, Kuo G, Weiner AJ, Overby LR, Bradley DW, Houghton M (1989) Isolation of a cDNA clone derived from a blood-borne non-A, non-B viral hepatitis genome. Science 244: 359-362

5. de Haan CA, Vennema H, Rottier PJ (2000) Assembly of the coronavirus envelope: homotypic interactions between the M proteins. J Virol 74: 4967-4978

6. Drummer HE, Maerz A, Poumbourios P (2003) Cell surface expression of functional hepatitis C virus E1 and E2 glycoproteins. FEBS Lett 546: 385-390 
7. Dubuisson J (2000) Folding, assembly and subcellular localization of hepatitis C virus glycoproteins. Curr Top Microbiol Immunol 242: 135-148

8. Elroy-Stein O, Moss B (1990) Cytoplasmic expression system based on constitutive synthesis of bacteriophage T7 RNA polymerase in mammalian cells. Proc Natl Acad Sci USA 87: 6743-6747

9. Flint M, Logvinoff C, Rice CM, McKeating JA (2004) Characterization of infectious retroviral pseudotype particles bearing hepatitis C virus glycoproteins. J Virol 78: 6875-6882

10. Fuerst TR, Niles EG, Studier FW, Moss B (1986) Eukaryotic transient-expression system based on recombinant vaccinia virus that synthesizes bacteriophage T7 RNA polymerase. Proc Natl Acad Sci USA 83: 8122-8126

11. Godeke GJ, de Haan CA, Rossen JW, Vennema H, Rottier PJ (2000) Assembly of spikes into coronavirus particles is mediated by the carboxy-terminal domain of the spike protein. J Virol 74: 1566-1571

12. Gould SJ, Booth AM, Hildreth JE (2003) The Trojan exosome hypothesis. Proc Natl Acad Sci USA 100: 10592-10597. Epub 2003 Aug 28

13. Haijema BJ, Volders H, Rottier PJ (2003) Switching species tropism: an effective way to manipulate the feline coronavirus genome. J Virol 77: 4528-4538

14. Hsu M, Zhang J, Flint M, Logvinoff C, Cheng-Mayer C, Rice CM, McKeating JA (2003) Hepatitis C virus glycoproteins mediate $\mathrm{pH}$-dependent cell entry of pseudotyped retroviral particles. Proc Natl Acad Sci USA 100: 7271-7276. Epub 2003 May 21

15. Klumperman J, Locker JK, Meijer A, Horzinek MC, Geuze HJ, Rottier PJ (1994) Coronavirus $\mathrm{M}$ proteins accumulate in the Golgi complex beyond the site of virion budding. J Virol 68: 6523-6534

16. Krijnse-Locker J, Ericsson M, Rottier PJ, Griffiths G (1994) Characterization of the budding compartment of mouse hepatitis virus: evidence that transport from the RER to the Golgi complex requires only one vesicular transport step. J Cell Biol 124: 55-70

17. Kuo G, Choo QL, Alter HJ, Gitnick GL, Redeker AG, Purcell RH, Miyamura T, Dienstag JL, Alter MJ, Stevens CE, et al. (1989) An assay for circulating antibodies to a major etiologic virus of human non-A, non-B hepatitis. Science 244: 362-364

18. Kuo L, Godeke GJ, Raamsman MJ, Masters PS, Rottier PJ (2000) Retargeting of coronavirus by substitution of the spike glycoprotein ectodomain: crossing the host cell species barrier. J Virol 74: 1393-1406

19. Lagging LM, Meyer K, Owens RJ, Ray R (1998) Functional role of hepatitis C virus chimeric glycoproteins in the infectivity of pseudotyped virus. J Virol 72: 3539-3546

20. Lauer GM, Walker BD (2001) Hepatitis C virus infection. N Engl J Med 345: 41-52

21. Lindenbach BD, Evans MJ, Syder AJ, Wolk B, Tellinghuisen TL, Liu CC, Maruyama T, Hynes RO, Burton DR, McKeating JA, Rice CM (2005) Complete replication of hepatitis $\mathrm{C}$ virus in cell culture. Science 309: 623-626. Epub 2005 June 9

22. Lozach PY, Amara A, Bartosch B, Virelizier JL, Arenzana-Seisdedos F, Cosset FL, Altmeyer R (2004) C-type lectins L-SIGN and DC-SIGN capture and transmit infectious hepatitis C virus pseudotype particles. J Biol Chem 279: 32035-32045. Epub 2004 May 27

23. Martire G, Viola A, Iodice L, Lotti LV, Gradini R, Bonatti S (2001) Hepatitis C virus structural proteins reside in the endoplasmic reticulum as well as in the intermediate compartment/cis-Golgi complex region of stably transfected cells. Virology 280: 176-182

24. Matsuura Y, Tani H, Suzuki K, Kimura-Someya T, Suzuki R, Aizaki H, Ishii K, Moriishi K, Robison CS, Whitt MA, Miyamura T (2001) Characterization of pseudotype VSV possessing HCV envelope proteins. Virology 286: 263-275 
25. Meyer K, Basu A, Ray R (2000) Functional features of hepatitis C virus glycoproteins for pseudotype virus entry into mammalian cells. Virology 276: 214-226

26. Mottola G, Jourdan N, Castaldo G, Malagolini N, Lahm A, Serafini-Cessi F, Migliaccio G, Bonatti S (2000) A new determinant of endoplasmic reticulum localization is contained in the juxtamembrane region of the ectodomain of hepatitis $\mathrm{C}$ virus glycoprotein E1. J Biol Chem 275: 24070-24079

27. Mottola G, Cardinali G, Ceccacci A, Trozzi C, Bartholomew L, Torrisi MR, Pedrazzini E, Bonatti S, Migliaccio G (2002) Hepatitis C virus nonstructural proteins are localized in a modified endoplasmic reticulum of cells expressing viral subgenomic replicons. Virology 293: 31-43

28. Rottier PJ, Horzinek MC, van der Zeijst BA (1981) Viral protein synthesis in mouse hepatitis virus strain A59-infected cells: effect of tunicamycin. J Virol 40: 350-357

29. Sandrin V, Boulanger P, Penin F, Granier C, Cosset FL, Bartosch B (2005) Assembly of functional hepatitis $\mathrm{C}$ virus glycoproteins on infectious pseudoparticles occurs intracellularly and requires concomitant incorporation of E1 and E2 glycoproteins. J Gen Virol 86: 3189-3199

30. Schweizer A, Fransen JA, Bachi T, Ginsel L, Hauri HP (1988) Identification, by a monoclonal antibody, of a $53-\mathrm{kD}$ protein associated with a tubulo-vesicular compartment at the cis-side of the Golgi apparatus. J Cell Biol 107: 1643-1653

31. Takamizawa A, Mori C, Fuke I, Manabe S, Murakami S, Fujita J, Onishi E, Andoh T, Yoshida I, Okayama H (1991) Structure and organization of the hepatitis $C$ virus genome isolated from human carriers. J Virol 65: 1105-1113

32. Tooze SA, Tooze J, Warren G (1988) Site of addition of N-acetyl-galactosamine to the E1 glycoprotein of mouse hepatitis virus-A59. J Cell Biol 106: 1475-1487

33. Vennema H, Heijnen L, Zijderveld A, Horzinek MC, Spaan WJ (1990) Intracellular transport of recombinant coronavirus spike proteins: implications for virus assembly. J Virol 64: 339-346

34. Vennema H, Rijnbrand R, Heijnen L, Horzinek MC, Spaan WJ (1991) Enhancement of the vaccinia virus/phage T7 RNA polymerase expression system using encephalomyocarditis virus 5'-untranslated region sequences. Gene 108: 201-209

35. Vennema H, Godeke GJ, Rossen JW, Voorhout WF, Horzinek MC, Opstelten DJ, Rottier PJ (1996) Nucleocapsid-independent assembly of coronavirus-like particles by co-expression of viral envelope protein genes. Embo J 15: 2020-2028

36. Voisset C, Dubuisson J (2004) Functional hepatitis C virus envelope glycoproteins. Biol Cell 96: 413-420

37. Wakita T, Pietschmann T, Kato T, Date T, Miyamoto M, Zhao Z, Murthy K, Habermann A, Krausslich HG, Mizokami M, Bartenschlager R, Liang TJ (2005) Production of infectious hepatitis $C$ virus in tissue culture from a cloned viral genome. Nat Med 11: 791-796. Epub 2005 June 12

38. Zhong J, Gastaminza P, Cheng G, Kapadia S, Kato T, Burton DR, Wieland SF, Uprichard SL, Wakita T, Chisari FV (2005) Robust hepatitis C virus infection in vitro. Proc Natl Acad Sci USA 102: 9294-9299. Epub 2005 June 6

Author's address: Stefano Bonatti, Dipartimento di Biochimica e Biotecnologie Mediche, Università di Napoli “Federico II”, via S. Pansini 5, 80131 Napoli, Italy; e-mail: bonatti@ unina.it 